Please do not remove this page

RMIT

UNIVERSITY

\title{
Rescaling
}

\section{Lobato, Ramon}

https://researchrepository.rmit.edu.au/esploro/outputs/9921863334401341/filesAndLinks?institution=61RMIT_INST\&index=null

Lobato, R. (2018). Rescaling. In Routledge Handbook of Interdisciplinary Research Methods (pp. 68-70).

Routledge. https://doi.org/10.4324/9781315714523

Document Version: Accepted Manuscript

Published Version: https://doi.org/10.4324/9781315714523

Repository homepage: https://researchrepository.rmit.edu.au (c) 2018 selection and editorial matter, Celia Lury, Rachel Fensham, Alexandra Heller-Nicholas, Sybille Lammes, Angela Last, Mike Michael and Emma Uprichard; individual chapters, the contributors

Downloaded On 2023/04/26 20:35:57 +1000 
Thank you for downloading this document from the RMIT Research Repository.

The RMIT Research Repository is an open access database showcasing the research outputs of RMIT University researchers.

RMIT Research Repository: http://researchbank.rmit.edu.au/

\section{Citation:}

Lobato, R 2018, 'Rescaling' in Celia Lury, Rachel Fensham, Alexandra Heller-Nicholas, Sybille Lammes, Angela Last, Mike Michael, Emma Uprichard (ed.) Routledge Handbook of Interdisciplinary Research Methods, Routledge, Oxon, United Kingdom, pp. 68-70.

See this record in the RMIT Research Repository at:

https://researchbank.rmit.edu.au/view/rmit:50382

Version: Accepted Manuscript

\section{Copyright Statement:}

(C) 2018 selection and editorial matter, Celia Lury, Rachel Fensham, Alexandra Heller-Nicholas, Sybille Lammes, Angela Last, Mike Michael and Emma Uprichard; individual chapters, the contributors

\section{Link to Published Version:}

https://doi.org/10.4324/9781315714523 


\title{
RESCALING
}

\section{Ramon Lobato}

Aug 2016

\author{
Published in Routledge Handbook of Interdisciplinary Research Methods, \\ eds. Celia Lury et al (Routledge, 2018) \\ Pre-press version
}

This essay reflects on a tactic I call rescaling, which involves manipulating notions of scale in research design. It is not a formal methodology; rather, it is a sort of impulse, or perhaps a flexible methodological device, that can be useful for illuminating relations between apparently disconnected phenomena. In what follows I discuss how rescaling can potentially be used within my own field of media and communications research, and perhaps in some other fields as well.

The context in which I have come to think about these issues is through undertaking research projects on digital media industries, and in particular on those productive elements of the media that exist outside the boundaries of "industry" per se (Lobato and Thomas 2015) - examples include free software, piracy, and user-generated content. Such research presents specific methodological challenges. For example, there are obvious difficulties with data collection, reliability and sampling when studying systems that are, by nature, informal and ephemeral. Second, there is the problem of finding the right analytical tools for the job. Methods used to study industry do not always work well in the world of media, and methods used to study media do not always work well for industries. I found it was necessary to cobble together a framework from a variety of disciplines, drawing on ideas from economic anthropology, political economy, and cultural studies as needed, and trying to work across social science and humanities approaches. Undertaking this research has 
been difficult, but it has also been generative from a methodological perspective because of the need to improvise.

One consequence of this research is that I have begun to think a lot about scale, and how it can be tweaked and inverted for the purposes of research design. Scale in research is about, among other things, the interdependence between the big and the small, and how we conceptualize this relationship in our data collection and interpretation. When studying industries, for example, we make certain kinds of choices about what counts most in the analysis and at what level of "the economy" these things are located. In other words, we enact an imaginary vertical ordering of the elements that make up an economy. But as geographers including Agnew (1993) and Allen (2011) remind us, notions of scale are always socially constructed and have real-world effects that can be illuminated in and through moments of scalar tension. As Marston (2000: 220) writes, "scale is not necessarily a preordained hierarchical framework for ordering the world - local, regional, national and global" but rather "a contingent outcome of the tensions that exist between structural forces and the practices of human agents".

Scale as a critical concept can be traced back through various intellectual traditions. Feminist and postcolonial theory, for example, have given us powerful tools with which to understand the relationship between big and small; so have anthropology, social history and development studies, in their emphasis on the interdependence of structural forces and everyday lifeworlds. And then there are the many literary and artistic provocations that ask us to see the big and the small in new ways (including surrealism and the writing of Georges Perec). So we have an array of conceptual resources available to us when thinking about scale.

Within social science research on industries, the problem of scale often finds expression in the tension between macro and micro levels of analysis. At the top end social science is of course well served (or poorly served, depending on your view) by structural theories of economic change. These approaches often mirror a particular kind of relationship of scale; in 
other words, experts use "big" frameworks - including political economy and regulatory theory - to study big things, like multinational corporations and government policy development. In media industry research, this often translates into "a political-economic perspective that emphasizes macrolevel structural issues of regulatory regimes, concentration of media ownership, historical change, and their larger connection to capital interests" (Havens et al 2009: 234).

Like all ways of knowing, such methods have limitations. Tools such as the HerfindahlHirschman index, for example, which measures levels of industry concentration using a scale from 0 to 1 , rely on the kind of financial data that is normally only available for publicly listed companies. From this perspective a lot of what passes for industry research has an in-built bias towards a particular ontology of large, listed firms, which are often taken to be constitutive of industry more generally. In other words, standard tools of economic analysis tend to reflect and produce certain ideas about what industries are -ideas that are culturally and historically specific. This particular model does not always translate well to cultural and media industry research, for example, because some parts of these industries have quite different organizational logics.

A parallel tradition of research takes a micro-level view of industries using micro-level methods. This approach is associated more with economic anthropology, certain forms of cultural sociology, and, in the humanities, cultural studies and cultural history, which tend to think of industries as structured formations of people, power and discourse. From this perspective, industries can be investigated by looking at the people and practices that constitute them, so the first step in research is to generate detailed and contextualised accounts of everyday practices at ground level. In this "bottom-up" tradition we therefore often find situated studies of cultural workers and professionals, grounded in ethnographic and qualitative interview traditions (Caldwell 2008, Hesmondhalgh and Baker 2009), as well as close analysis of industry discourses and "trade talk". This is the arena of modest claims, rigorous theorization, reflexivity, and grounded speculation, where knowledge is understood as provisional and situated. 
These patterns will be familiar to many readers as reflecting the epistemological cleavage between empirical social science and interpretive humanities traditions - something regularly attacked within the flattened ontologies of actor-network theory, nonrepresentational theory, and ecological and topological epistemologies. This cleavage is rarely so stark in practice because the correspondence between macro and micro methods and objects of study can be - and often is - productively inverted by juxtaposing different scales. For example, across existing media industry research one can find many examples of research projects that use bottom-up methods to study large things (as in the ethnography of media institutions), or top-down methods to study small things (as when researchers use methods like network analysis to study small online communities).

Let me provide some examples to illustrate the point. In recent research projects, I have studied a range of actors in media industries (included executives, fans, pirates and geeks); observed activities in retail sites and online spaces; scrutinized web forums; read archives of leaked material; analysed pricing patterns; compiled biographies of key individuals and case studies of typical companies; and so on. Over the course of this research I learned through trial and error that interesting findings tend to emerge when I applied the "wrong" scalar approach, sometimes by accident. For example, when investigating the economic dynamics of pirate DVD vending it was quite useful to spend part of the interview asking the kind of questions one would ask a corporate executive. Who is your competition? How much do you charge for your products, and why? Where do you get your stock from? Who works for you, and how do you manage them? This helped to cut quite quickly to the commercial realities structuring what is, after all, a commercial operation. In other words it was necessary to rescale my assumptions about the methods appropriate to these actors.

A second example comes out of a project I have recently been doing on the anonmyization and personal privacy software industry. This is a most unusual industry to study because it is highly fragmented, with very low barriers to entry, and many companies operate as bedroom enterprises. It has no industry associations and no central sources of data. Yet it 
has all the dynamics of any other commercial sector, including fierce competition, differentiation, professionalization, and labour mobility. To analyse this industry we did some of the things that one would do when studying a "big" industry: compiled an international database of known companies; collected data on server locations, price points and marketing strategies; and interviewed company representatives willing to speak on the record. But we also had to use the micro-level methods associated with qualitative research: hanging out in online spaces, signing up for various services and trying them out, discourse analysis of promotional materials, and so forth. And during interviews, it was helpful to mix up the micro and macro scales by interspersing data-oriented questions ("how many staff do you have, and where are they located?") with questions inviting more textured, qualitative responses ("take me through your average working day").

What I want to suggest is that these inversions of scale can be understood as a kind of methodological tactic. In other words, juxtaposing the big and the small - and the methodological orientations associated with each scale - often produces useful insights. This is not a radical proposition; nor is it new. But I find that playing around with notions of scale can be useful as an exploratory process when devising a research programme, even when we are investigating the "hard" stuff of firms, industries, revenues, and so on. Translating these ideas into research practice provides a framework for experimenting with macro and micro scales and the methodologies associated with each - a framework that I have found well suited to studying the unfamiliar institutional forms of digital media, but which may also be useful as an exploratory device in other fields as well. 


\section{References}

Agnew, J 1993, 'Representing space: Space, scale and culture in social science', in J Duncan and D Ley (eds), Place/culture/representation, Routledge, London, pp. 251-271.

Allen, J 2011, 'Topological twists: Power's shifting geographies', Dialogues in Human Geography, vol. 1, no. 3, pp. 283-298.

Caldwell, J 2008, Production Culture: Industrial Reflexivity and Critical Practice in Film and Television, Duke University Press, Durham.

Havens, T, Lotz, A, and Tinic, S 2009, 'Critical media industry studies: A research approach', Communication, Culture \& Critique, vol. 2, no. 2, pp. 234-253.

Hesmondhalgh, D and Baker, S 2011, Creative Labour: Media Work In Three Cultural Industries, Routledge, Abingdon.

Johnson, D, Kompare, D and Santo, A (eds) 2014, Making Media Work: Cultures of Management in the Entertainment Industries, NYU Press, New York.

Lobato, R and Thomas, J 2015, The Informal Media Economy, Polity, Cambridge.

Marston, S A, 2000, 'The social construction of scale', Progress in Human Geography, vol. 24, no. 2, pp. 219-242. 